
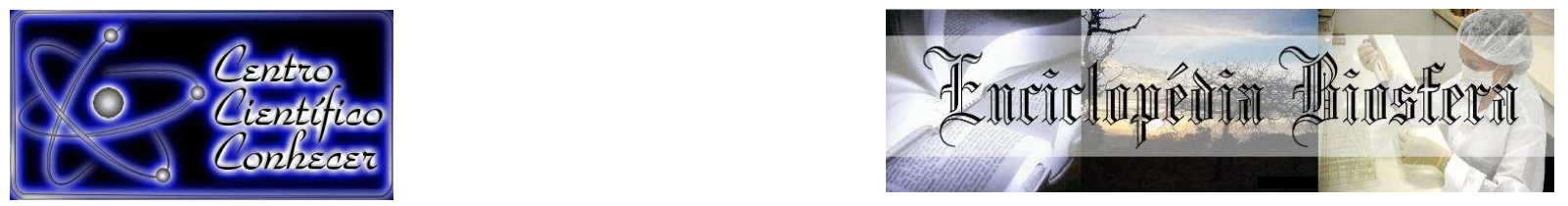

\title{
POTENCIAL MEDICINAL DE ESPÉCIES ARBÓREAS DE UM REMANESCENTE FLORESTAL DA FLORESTA ESTACIONAL SEMIDECIDUAL, NA REGIÃO CENTRAL DO ESTADO SÃO PAULO
}

\footnotetext{
Helena Souza Ronchi ${ }^{1}$, Filipe Pereira Giardini Bonfim ${ }^{3}$, Emily Toledo Coutinho ${ }^{2}$, Leonardo Augusto Martins ${ }^{4}$, Vera Lex Engel ${ }^{3}$.

${ }^{1}$ Engenheira Florestal, Mestranda do Programa de Pós Graduação em Agronomia:

Horticultura, FCA, UNESP Botucatu, São Paulo, Brasil. Email: hsronchi@gmail.com

${ }^{2}$ Graduanda em Engenharia Florestal, FCA, UNESP Botucatu, São Paulo, Brasil.

${ }^{3}$ Professor Assistente Doutor da Faculdade de Ciências Agronômicas, UNESP Botucatu, São Paulo, Brasil.

${ }^{4}$ Engenheiro Florestal, Doutorando do Programa de Pós Graduação em Ciências Florestais, FCA, UNESP Botucatu, São Paulo, Brasil.

\section{Recebido em: 08/04/2016 - Aprovado em: 30/05/2016 - Publicado em: 20/06/2016}

DOI: 10.18677/Enciclopedia_Biosfera_2016_085
}

\begin{abstract}
Esse trabalho apresenta o potencial medicinal de espécies arbóreas encontradas em um fragmento de Floresta Estacional Semidecidual. O fragmento é uma área proposta para reserva legal da Fazenda Experimental da Unesp Botucatu, localizada na região central do Estado de São Paulo. Nessa área, fez-se levantamento florístico e foram identificadas 108 espécies arbóreas de 43 famílias. A partir das espécies identificadas realizou-se pesquisas em bancos de dados sobre o potencial medicinal destas espécies em questão, nos anos de 2014 e 2015. Das espécies encontradas, 46\% (51 espécies) possuem o potencial medicinal conhecido. Destas, a família que apresentou o maior potencial foi a Fabaceae, representando, aproximadamente, 31\% (16 espécies) do potencial medicinal do fragmento florestal. Outra análise deste estudo é que as partes utilizadas para fins medicinais são órgãos vegetais como (folhas, flor, casca, fruto) e que a exploração (desde que haja manejo adequado) não compromete a permanência do próprio indivíduo, mostrando assim, estratégia de valorização das florestas em pé. Isso também indica alternativa de produção para áreas onde é permitido o uso das espécies sem que comprometa a existência delas, como é o caso das reservas legais, áreas de proteção dos mananciais, entre outros. Portanto, conhecer os potenciais usos das espécies florestais é o primeiro passo para conhecer a real capacidade das florestas de fornecer insumos.
\end{abstract}

PALAVRAS-CHAVE: espécies nativas, plantas medicinais, produtos florestais não madeireiros. 


\title{
POTENTIAL MEDICINAL FROM ARBOREAL SPECIES OF REMNANT FOREST BELONG SEMIDECIDUAL STACIONAL FOREST IN CENTRAL REGION OF SÃO PAULO STATE
}

\begin{abstract}
This work presents the medicinal of tree species found in a forest fragment Semideciduous. The fragment is an area proposed for Experimental Farm of the legal reserve of Unesp Botucatu, located in the central region of São Paulo State. In this area, there was a floristic survey and have identified 108 tree species from 43 families. From the identified species was carried out a literature review of medicinal potential. Of the species found $46 \%$ (51 species) are known medicinal potential. Of these, the family that had the greatest potential was the Fabaceae, representing approximately $31 \%$ (16 species) of the medical potential of the forest fragment. Another analysis of this study is that the parts used for both medicinal action are plant organs (leaves, flower, bark, fruit) that the operation (provided there is an adequate management) does not compromise the individual's own residence, showing a valuation of standing forests strategy. This also indicates an alternative production to areas where it is allowed the use of species without compromising their existence, such as legal reserves, protected areas of water sources, among others. Therefore, knowing the potential uses of forest species is the first step to know the real capacity of forests to provide inputs.
\end{abstract}

KEYWORDS: medicinal plants, native species, non timber forest products.

\section{INTRODUÇÃO}

O setor florestal, segundo o Serviço Florestal Brasileiro, representa 3,5\% do Produto Interno Bruto do Brasil (PIB) e 7,3\% das exportações totais do país. Em contraste a esses números, os ecossistemas florestais nativos convivem com altos índices de desmatamento ilegal e com a carência de políticas econômicas, pesquisas e incentivo financeiro (ZAKIA et al., 2012). Como consequência, isso acarreta uma expressiva diminuição da porcentagem florestal do território brasileiro, aumentando a fragmentação dos habitats e inúmeras perdas na diversidade biológica, como cita NETO \& BENTO (2015) em suas avaliações quanto ao Bioma Mata Atlântica. Além disso, a retirada das florestas implica na descontinuidade de serviços ambientais essenciais para o ser humano, como ressalta NOBRE (2014).

A estratégia de utilização da floresta de maneira racional, a fim de minimizar os impactos aos ecossistemas florestais, tem sido cada vez mais reconhecida. Os produtos florestais não madeireiros (PFMN), outras partes vegetais da planta que não são madeira, têm ganhado destaque, pois além de manter as florestas em pé, já que estão dentro do sistema produtivo, promovem desenvolvimento social e econômico. Manejar, de maneira adequada, esses produtos não compromete a permanência do próprio indivíduo manejado, pois as partes utilizadas como matéria prima (casca, folhas, fruto, óleos, látex) não implicam na derrubada do indivíduo. Desta forma, o aproveitamento de produtos florestais não madeireiros pode se tornar alternativa sustentável, visto que abrange o domínio socioeconômico e ecológico por meio do manejo correto dos recursos naturais (SANTOS, 20013; IMAFLORA, 2014).

Essa ação ainda resgata o etnoconhecimento relacionado às propriedades curativas das espécies. Porém, muito destes conhecimentos foram perdidos com 0 ENCICLOPÉDIA BIOSFERA, Centro Científico Conhecer - Goiânia, v.13 n.23; p. 9872016 
avanço tecnológico, e outros meios de tratamento medicinal foram surgindo assim como novos medicamentos, que de certa forma, desvaloriza o conhecimento popular (BADEK \& RESSEL, 2011).

Contudo, é primordial o desenvolvimento de estratégias de conservação e resgate cultural, para que se torne possível fornecer subsídios para a perpetuação de espécies. Isto favorece a valorização da riqueza florística local e da conservação dos fragmentos de Mata Atlântica, de modo a reduzir os impactos sobre a biodiversidade. Nesse sentido, objetivou-se conhecer o potencial medicinal das espécies florestais arbóreas, como também avaliar a parte vegetal utilizada para extrair o princípio ativo, contribuindo com estratégias de produção e conservação de florestas.

\section{MATERIAL E MÉTODOS}

A área em que se fez o levantamento dendrológico, denominada de Área 2 (Figura 1), compreende um dos poucos remanescentes de floresta estacional semidecidual do estado de São Paulo, localizado dentro da Fazenda Experimental Edgárdia pertencente à Universidade Estadual Paulista, UNESP, em Botucatu (latitude: 22 ' 49', S e longitude: 48'23, W).

O fragmento situa-se na encosta da cuesta de Botucatu, numa altitude 470 a 750 $\mathrm{m}$ altitude, em área com solo de classificação argissolo vermelho-amarelo (AVA), álico, de textura areno-franca, com relevo suave ondulado a ondulado (NOGUEIRA Jr., 2000). A condição climática é baseada na classificação de Koeppen, do tipo Cfa: Clima Temperado (Mesotérmico) úmido, com temperaturas médias (nos meses quentes), superior a $22^{\circ} \mathrm{C}$ (FONSECA \& RODRIGUES, 2000; CUNHA \& MARTINS, 2009).

A metodologia do levantamento florístico do estrato arbóreo foi baseada em idas ao campo, pelas trilhas existentes nos fragmento, pelo método turnê-guiada (ALBURQUE \& LUCENA, 2004). De cada indivíduo foi realizada a coleta de ramos com folhas, e, quando possível, flores e/ou frutos.

Também foram anotados em caderneta de campo, os detalhes do tronco (casca externa e interna), e das características organolépticas da espécie. Todo material coletado foi fotografado, prensado, herborizado e depositado no herbário. A identificação das espécies foi feita utilizando-se as anotações da caderneta de campo, juntamente com chaves analíticas, guias e floras de identificação de famílias, gêneros e espécies (LORENZI, 2002), bem como por meio da comparação com herbários de referência.

A partir do levantamento dendrológico, realizou-se revisões bibliográficas sobre o potencial medicinal das espécies identificadas, utilizando-se dados de pesquisas relacionadas às espécies em questão, nas plataformas PubMed, Scielo, Web of Science, entre outras bases de dados, nos anos de 2014 e 2015. 


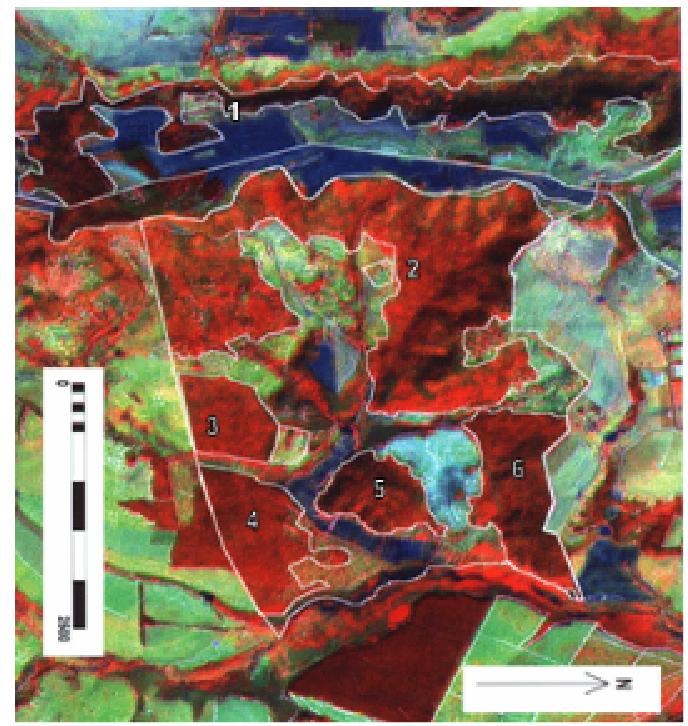

FIGURA 1 Imagem de satélite das Fazendas

Edgardia e Lageado (limites em branco).

\section{RESULTADOS E DISCUSSÃO}

Das famílias encontradas, a que apresentou o maior número de espécies foi a Fabaceae com $24,32 \%$ do total (27 de 111), seguido por Meliaceae $(7,21 \%)$, Myrtaceae e Rutaceae (6,31\%), Euphorbiaceae (5,41\%), Malvaceae e Solanaceae (4,50\%) (Figura 2). As famílias Fabaceae e Meliaceae também apresentaram a maior quantidade de indivíduos em um fragmento de Floresta Estacional Semidecidual na Serra do cipó, no estado de Minas Gerais (SANTOS, et al. 2012). O mesmo foi observado por BRAGA et al. (2011), estudando o mesmo tipo de vegetação, na cidade de Viçosa, Minas Gerais.

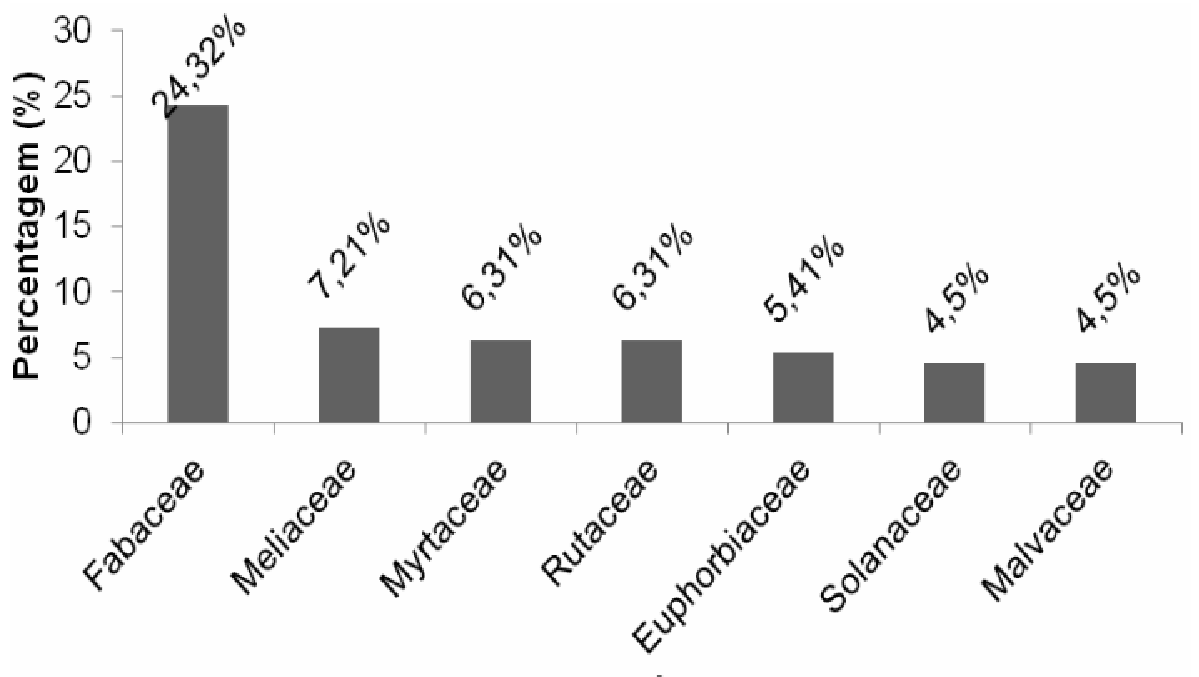

Famílias

FIGURA 2 Proporção (\%) de espécies de algumas famílias botânicas do fragmento 2 . 
Dentro do potencial medicinal, dessas espécies identificadas, 46\% (51 espécies) das espécies encontradas possuem o potencial medicinal conhecido (QUADRO 1). E assim como no número de espécies, a família Fabaceae também apresentou o maior número de espécies com potencial medicinal, representando por, aproximadamente, 31\% (16 espécies) do potencial medicinal do fragmento florestal. Dessas, 14 espécies possuem algum uso etnofarmacológico e dessas, 11 espécies relacionam seu uso etnofarmacológico com estudos laboratoriais elucidados cientificamente.

RODRIGUES \& CARVALHO (2010), por meio de entrevistas com moradores locais de uma região do mesmo subtipo de floresta, em Minas Gerais, identificaram que a família Fabaceae foi o que mais apresentou potencial medicinal. Além disso, os autores descrevem que $61,27 \%$ das espécies, com o potencial possuem o hábito arbóreo. Já VIEIRA et al. (2013) obtiveram em seu estudo que as famílias Asteraceae, Fabaceae e Piperaceae são as mais representativas do levantamento dentro do potencial, realizado em um fragmento de Mata Atlântica situado na Fazenda Azulão, em Dourados-MS. Enquanto BARATA-SILVA, et al. (2015), estudando diferentes áreas no Rio Grande do Sul, verificaram que a família mais representativa com potencial farmacológico foi a Myrtaceae.

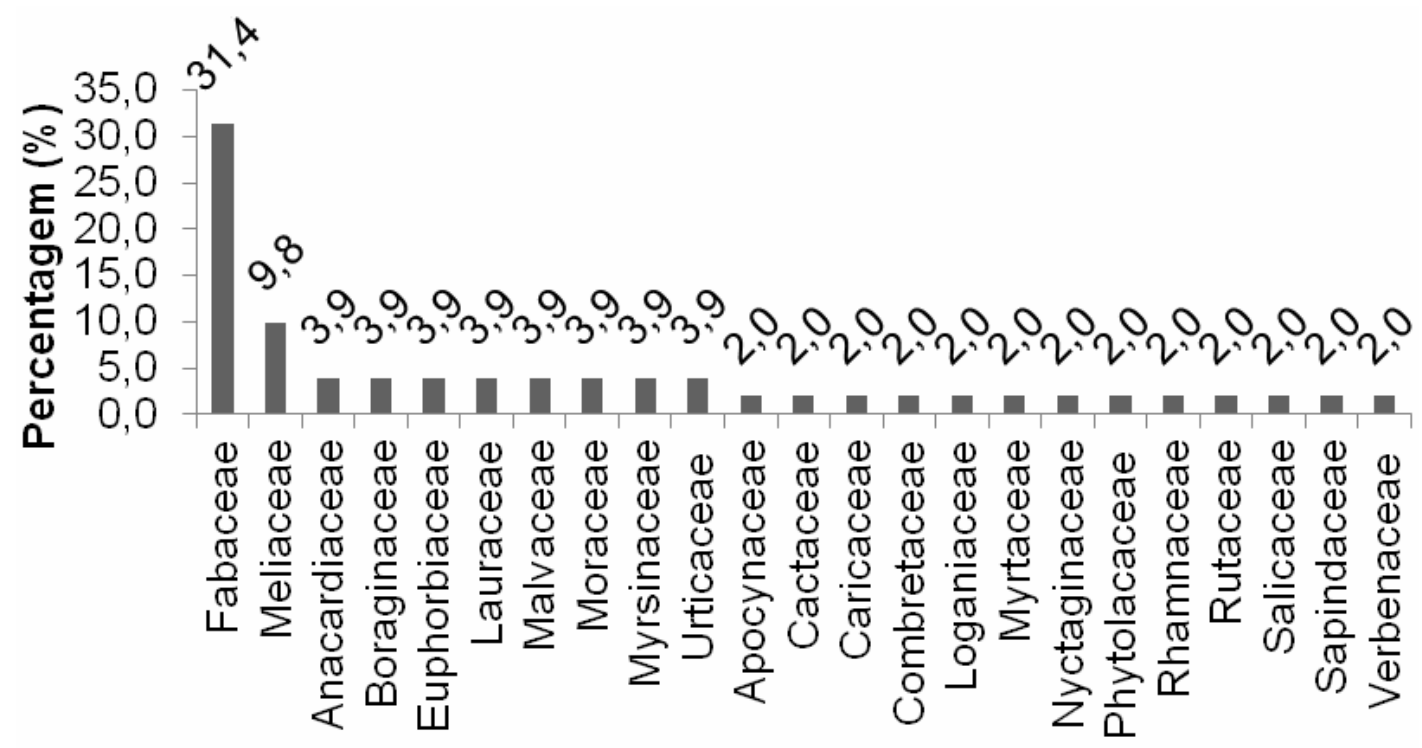

Famílias

FIGURA 3 Potencial medicinal das famílias botânicas presente no fragmento florestal expresso em porcentagem (\%).

Dentre as ações medicinais dessa família, dá-se destaque efeito antiinflamatório e diurético, onde $25 \%$ das espécies possuem ação antiinflamatoira e $25 \%$ das espécies possui a diurética. Caracterizando os principais potenciais da Familia. As espécies que se destacaram dentro dessas ações medicinais são a Bauhinia forficata Link e a Copaifera officinalis (Jacq.) L. 


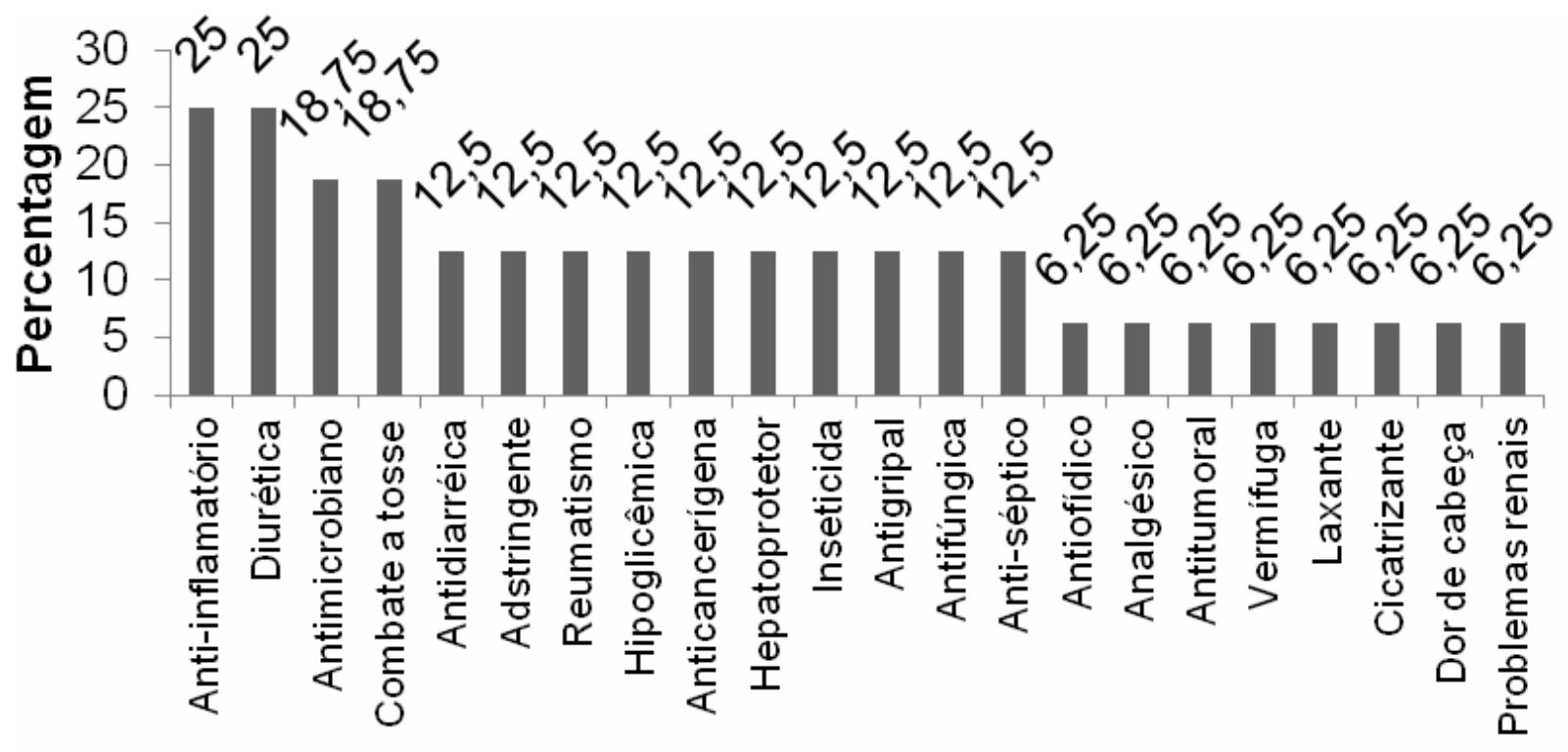

\section{Uso medicinal}

FIGURA 4 Uso medicinal das espécies florestais (família Fabaceae) encontradas no fragmento florestal expresso em porcentagem (\%).

Como uma das maiores representantes da família Fabaceae, com ampla aparição na Floresta Atlântica, Bauhinia forficata Link vem despertando vasto interesse no meio acadêmico, devido sua variedade de uso no âmbito medicinal, dentre eles ação diurética e hipoglicêmica, possui uso bem definido se destacando em estudos fitoquímicos (LÓPEZ \& SANTOS, 2015). Já Copaifera officinalis (Jacq.) L. destaca-se por suas propriedades analgésicas, anti-inflamatórias, bactericidas e cicatrizantes. Os efeitos farmacológicos do óleo da copaíba e suas aplicações terapêuticas estão despertando a atenção de estudiosos da área assim como da indústria farmacêutica, que vem investigando suas propriedades, porém, ainda é necessária a realização de estudos mais aprofundados na área assim como metodologias, para comprovar a ação do óleo de copaíba no processo cicatricial e seus possíveis efeitos tóxicos. (MONTES, et al. 2009).

Contudo, apesar do grande interesse industrial, ressalta-se que a alta demanda sobre o comércio dessas espécies com princípios ativos pode ocasionar uma pressão sobre as mesmas (AZEVEDO \& SILVA, 2005). Devido a isso, é primordial a execução de estudos complementares, a fim de garantir que haja um manejo correto, prevendo uma extração racional dos recursos da floresta.

Outra análise que pode ser realizada consiste na discriminação das partes vegetais utilizadas para a extração do princípio ativo para ação medicinal. São órgãos vegetais que quando extraídos em certas quantidades, não comprometem o indivíduo arbóreo, mantendo-o dentro do sistema produtivo, diferentemente quando o objetivo é madeira para construções e móveis. Porém, é imprescindível que haja estudos que avaliem o custo benefício da retirada dos produtos farmacológicos, prevendo relações 
econômicas e ecológicas, assim como a quantidade que é possível ser extraída de cada indivíduo para que se garanta a sua sobrevivência.

A casca é a mais representativa na retirada dos princípios ativos, com $29,4 \%$ seguida das folhas e dos galhos, com $23,5 \%$ e $14,7 \%$, respectivamente. Ressalta-se que a retirada de cascas diretamente do tronco da árvore pode trazer prejuízos à sobrevivência do individuo, sendo melhor, portanto, retirar as cascas de galhos podados, que além de garantir a manutenção da planta na área, ainda contribui para seu incremento (BORGES FILHO \& FELFILI, 2003). BARATA-SILVA et al. (2005) estudando o uso de plantas arbóreas no Rio grande do Sul, constataram que há predominância no uso das folhas $(83 \%)$, em relação as outras partes vegetais, nas preparações dos remédios. Esse órgão vegetal também foi citado por FERREIRA et al. (2014), como mais utilizado na manipulação dos remédios.

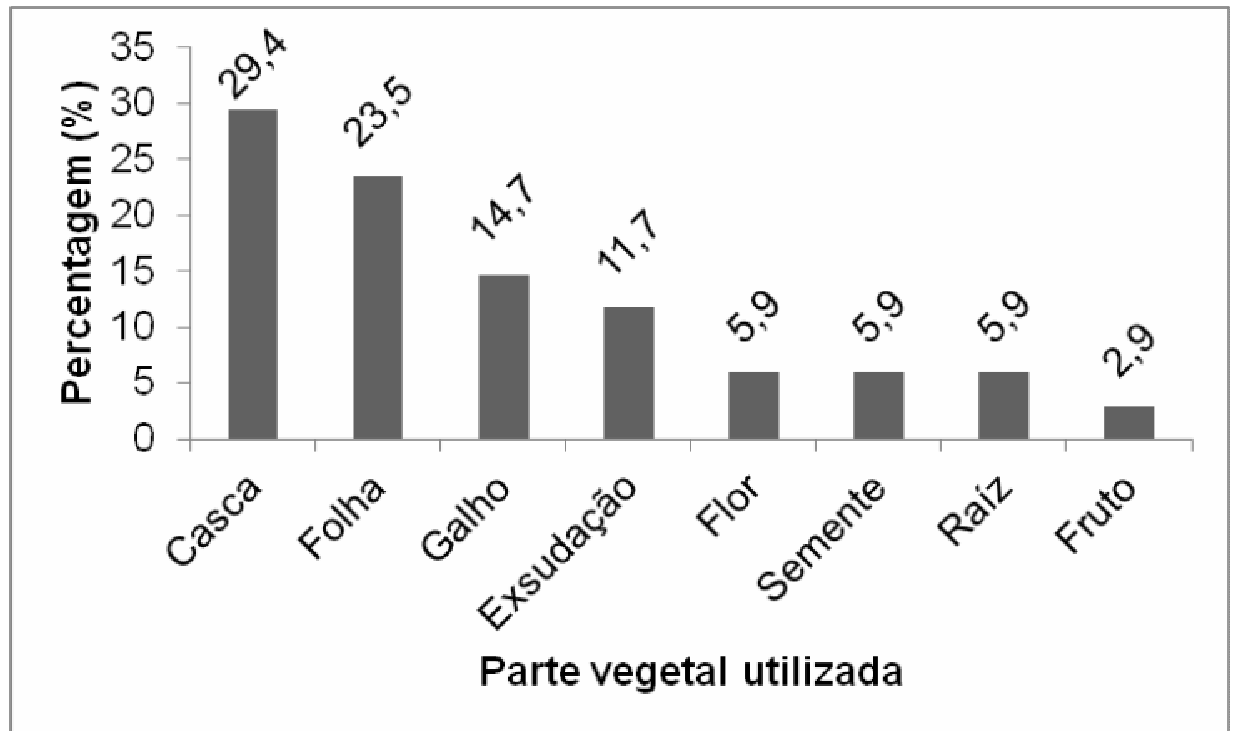

FIGURA 5 Relação das partes vegetais utilizadas com princípios farmacológicos da família Fabaceae.

\section{CONCLUSÃO}

Existe uma grande variedade de espécies florestais nativas, da Floresta Estacional Semidecidual, que pode ser utilizada com fins medicinais, dando destaque a Família Fabaceae.

Observa-se também, que as partes vegetais usadas para a extração do principio ativo são classificados como produtos florestais não madeireiros. 
QUADRO 1: Relação das espécies arbóreas com potencial medicinal no remanescente florestal.

\begin{tabular}{|c|c|c|c|}
\hline Família & Nome popular & Nome científico & Parte utilizada \\
\hline \multirow[t]{2}{*}{ Anacardiaceae } & Aroeira-vermelha & Schinus terebinthifolius Raddi & Folhas e frutos \\
\hline & Peito-de-pombo & Tapirira guianensis & Casca \\
\hline Apocynaceae & Guatambu & Aspidosperma ramiflorum Müll Arg. & Caule e folha \\
\hline \multirow[t]{2}{*}{ Boraginaceae } & Porangaba & Cordia ecalyculata Vell. & Folhas, ramos novos \\
\hline & Guajuvira & Patagonula americana $L$. & Folhas \\
\hline Cactaceae & Mandacaru & Cereus peruvianus Mill & Calos \\
\hline Caricaceae & Jacaratiá/Mamão-do-mato & Jacaratia spinosa (Aubl.)A. DC & Fruto \\
\hline Combretaceae & Capitão-do-campo & Terminalia argentea (Cambess.) Mart. & Casca \\
\hline \multirow[t]{2}{*}{ Euphorbiaceae } & Tanheiro & Alchornea glandulosa Poepp.\& Endl & Folhas \\
\hline & Tapiá & Alchornea triplinervia(Spreng.) Müll Arg. & Folhas \\
\hline Fabaceae- Cercideae & Pata-de-vaca & Bauhinia forficata Link. & Folhas cascas flores \\
\hline \multirow{6}{*}{$\begin{array}{c}\text { Fabaceae } \\
\text { Caesalpinioideae }\end{array}$} & Copaíba & Copaifera langsdorffii Desf. & Seiva \\
\hline & Jatobá & Hymenaea courbaril L. var. stilbocarpa (Hayne) Lee \& Lang. & Casca e seiva \\
\hline & Alecrim de Campinas & Holocalyx balansae Micheli & Não identificada \\
\hline & Guapuruvu & Schizolobium parahyba (Vell.) Taub & Folhas \\
\hline & Canafístula & Peltophorum dubium (Spreng.) Taub. & Raiz, frutas e folhas \\
\hline & Amendoim Bravo & Pterogyne nitens Tul & Casca do caule \\
\hline Fabaceae - Faboideae & Araribá & Centrolobium tomentosum Guill. ex Benth. & Não identificada \\
\hline
\end{tabular}




\begin{tabular}{|c|c|c|c|}
\hline & bico-de-pato & Machaerium aculeatum Raddi. & Casca \\
\hline & sapuvinha & Machaerium stipitatum (DC.) Vog. & Casca \\
\hline & cabreúva & Myroxylon peruiferum L. F. & Folhas, fruto e casca \\
\hline & amendoim do campo & Platypodium elegans Vogel. & Não identificada \\
\hline \multirow{4}{*}{$\begin{array}{l}\text { Fabaceae - } \\
\text { Mimosoideae }\end{array}$} & monjoleiro & Acacia polyphylla A.DC & Resina \\
\hline & Tamboril & Enterolobium contorstisiliquum (Vell.) Morong. & Não identificada \\
\hline & Angico & Parapiptadenia rigida (Benth.) Brenan & Casca e fruto \\
\hline & pau-jacaré & Piptadenia gonoacantha (Mart.)J.F. Macbr. & Casca, galho e folha \\
\hline \multirow[t]{2}{*}{ Lauraceae } & canela & Nectandra grandiflora Nees \& Mart. exNees & Casca \\
\hline & canelinha & Nectandra megapotamica (Spreng.) Mez & Folha \\
\hline Loganiaceae & salta martim & Strychnos brasilienses Mart. & Casca da raiz \\
\hline \multirow[t]{2}{*}{ Malvaceae } & paineira & Ceiba speciosa (A.St. -Hil.) Dawson. & Casca \\
\hline & açoita-cavalo & Luehea divaricata Mart. & Folhas \\
\hline \multirow[t]{5}{*}{ Meliaceae } & canjarana & Cabralea canjerana Vell. & Folhas, raiz, caule e folha \\
\hline & cedro & Cedrela fissilis Vell. & Folhas e cascas \\
\hline & Taúva & Guarea guidonia & Todas as partes \\
\hline & catigua & Trichilia catigua A. Juss. & Casca \\
\hline & pau-ervilha & Trichilia elegans $A$. Juss. & Semente, folha, casca e raiz \\
\hline \multirow[t]{2}{*}{ Moraceae } & taiúva & Maclura tinctoria (L.) D.Don ex Steud. & Látex, casca \\
\hline & Espinheira-santa & Sorocea bonplandii ( Baill.) Burger, Lanj \& Boer & Folhas \\
\hline
\end{tabular}




\begin{tabular}{cccc}
\hline Myrsinaceae & capororoca & $\begin{array}{c}\text { Rapanea ferruginea (Ruiz \& Pav.) Mez (sin. Myrsine } \\
\text { coriacea (Sw.) R.Br. ex Roem. \& Schult.) }\end{array}$ & Folha e casca \\
& capororoca & Rapanea umbellata (Mart.) Mez & Fomos com folha \\
Myrtaceae & Goiaba & Psdium guajava $L$ & Casca \\
Nyctaginaceae & Maria-mole & Guapira opposita (Vell.) Reitz & Folha \\
Phytolacaceae & Pau d'alho & Gallesia integrifolia (Spreng.) Harms & Folhas \\
Rhamnaceae & Saguaragi & Rhamnidium elaeocarpum Reissek & Folhas, casca, raíz \\
Rutaceae & mamica-de-porca & Zanthoxylum rhoifolium Lam. & Folhas, casca \\
Salicaceae & lagarteiro & Casearia sylvestris Sw. & Casca \\
Sapindaceae & camboatã-branco & Matayba elaeagnoides Radlk & Folha \\
Urticaceae & urtigão & Urera baccifera (L.) Gaud. & Folhas \\
embauba & Cecropia pachystachia Trécul & Casca \\
Verbenaceae & Citharexylum myrianthum Cham. & \\
\hline
\end{tabular}


QUADRO 2: Relação das espécies arbóreas com potencial medicinal da Família Fabaceae

\begin{tabular}{|c|c|c|c|c|c|}
\hline Nome científico & $\begin{array}{l}\text { Nome(s) } \\
\text { popular(es) }\end{array}$ & Uso etnofarmacológico & $\begin{array}{l}\text { Parte } \\
\text { utilizada }\end{array}$ & $\begin{array}{ll}\text { Fins } & \text { medicinais } \\
\text { (comprovação científica) }\end{array}$ & $\begin{array}{l}\text { Parte } \\
\text { utilizada }\end{array}$ \\
\hline $\begin{array}{l}\text { Acacia polyphylla } \\
\text { DC. }\end{array}$ & $\begin{array}{l}\text { Monjoleiro, maricá, } \\
\text { Juqueri-guaçu, } \\
\text { paricá-branco, } \\
\text { paricarana-de- } \\
\text { espinhos }\end{array}$ & Combate a tosse. & Resina & $\begin{array}{l}\text { Inseticida, principalmente } \\
\text { contra Anagasta kuehniella }\end{array}$ & Casca \\
\hline $\begin{array}{l}\text { Bauhinia forficata } \\
\text { Link. }\end{array}$ & $\begin{array}{l}\text { Pata-de-vaca, } \\
\text { árvore orquídea, } \\
\text { bauínia, capa-bode }\end{array}$ & $\begin{array}{l}\text { As folhas são usadas na forma de } \\
\text { decocto para problemas renais e } \\
\text { reumatismo. Tanto as cascas } \\
\text { quanto as folhas (decocção ou } \\
\text { infusão) são usadas como } \\
\text { hipoglicemiante, nas afecções } \\
\text { renais, como diurético, } \\
\text { adstringente (casca) } \\
\text { hipocolesteremiante. } \\
\text { O decocto das folhas é usado } \\
\text { também pra picadas de cobras. }\end{array}$ & $\begin{array}{l}\text { cascas, } \\
\text { folhas, flores, } \\
\text { lenho, raízes }\end{array}$ & $\begin{array}{l}\text { Diabetes Antidiarréica, } \\
\text { depurativa, diurética, } \\
\text { hipocolesterolmiante, } \\
\text { hipoglicêmica } \\
\text { (antidiabética), laxante, } \\
\text { purgativa, tônica renal, } \\
\text { vermífuga. }\end{array}$ & $\begin{array}{l}\text { Cascas, } \\
\text { folhas, flores, } \\
\text { lenho, raízes }\end{array}$ \\
\hline $\begin{array}{l}\text { Bowdichia } \\
\text { virginoides Kunth. }\end{array}$ & $\begin{array}{l}\text { sucupira-do- } \\
\text { cerrado, sucupira- } \\
\text { açu cutiúba, } \\
\text { sapupira-do-campo, } \\
\text { sepifirme, sucupira- } \\
\text { amarela, sucupira- } \\
\text { da-praia, sebepira, } \\
\text { paricarana, acari- } \\
\text { açu. }\end{array}$ & $\begin{array}{l}\text { Além disso, é utilizada na } \\
\text { medicina popular para } \\
\text { combater diabetes, reumatismos } \\
\text { e inflamações em geral }\end{array}$ & Casca & $\begin{array}{l}\text { como analgésico nos casos } \\
\text { de reumatismo e artrose. }\end{array}$ & $\begin{array}{l}\text { Extrato fluido e } \\
\text { tintura da } \\
\text { casca }\end{array}$ \\
\hline $\begin{array}{l}\text { Centrolobium } \\
\text { tomentosum Guill. } \\
\text { ex Benth. }\end{array}$ & $\begin{array}{l}\text { Araribá, } \quad \text { pitimuju, } \\
\text { gororoba, putumuju, } \\
\text { ararivá, } \\
\text { rosa, carijó }\end{array}$ & $\begin{array}{l}\text { A infusão da } \\
\text { casca é ótimo remédio contra o } \\
\text { berne. }\end{array}$ & Cascas & $\begin{array}{l}\text { forte } \\
\text { adstringente. o emplastro } \\
\text { na cobertura de feridas e } \\
\text { contusões. }\end{array}$ & Casca e folhas \\
\hline $\begin{array}{l}\text { Copaifera } \\
\text { langsdorffii Desf. }\end{array}$ & $\begin{array}{l}\text { copaíba, copaibeira, } \\
\text { pau-de-óleo, } \\
\text { copaúva, copai, } \\
\text { copaibarana, } \\
\text { copaibo, copal, }\end{array}$ & $\begin{array}{l}\text { Utilizada pelos índios latino- } \\
\text { americanos para curar feridas de } \\
\text { guerreiros após batalhas e para } \\
\text { passar no coto umbilical de } \\
\text { recém-nascidos }\end{array}$ & óleo-resina & $\begin{array}{lr}\text { Inseticida, } & \text { atividade } \\
\text { antiinflamatória, } & \text { ação } \\
\text { cicatrizante, potencial anti- } \\
\text { séptico, } \\
\text { expectorante, diurético e }\end{array}$ & Óleo-resina \\
\hline
\end{tabular}

ENCICLOPÉDIA BIOSFERA, Centro Científico Conhecer - Goiânia, v.13 n.23; p. 


\begin{tabular}{|c|c|c|c|c|c|}
\hline $\begin{array}{l}\text { Enterolobium } \\
\text { contorstisiliquum } \\
\text { (Vell.) Morong. }\end{array}$ & $\begin{array}{l}\text { Orelha de negro, } \\
\text { tamboril, ximbuva }\end{array}$ & Reumatismo & Cascas & Tóxico, abortivo & $\begin{array}{l}\text { Cascas das } \\
\text { raízes }\end{array}$ \\
\hline $\begin{array}{l}\text { Holocalyx balansae } \\
\text { Micheli }\end{array}$ & $\begin{array}{l}\text { Pau alegrim, } \\
\text { Alegrim de } \\
\text { campinas }\end{array}$ & $\begin{array}{l}\text { antisséptico, } \\
\text { diaforético, excitante, tônico do } \\
\text { coração e do estômagotosse, } \\
\text { asma, coqueluche, gripe, febre, e } \\
\text { contusões } \\
\text { dor de cabeça }\end{array}$ & $\begin{array}{l}\text { Folha/ Chá e } \\
\text { banho }\end{array}$ & Nada consta & Nada consta \\
\hline $\begin{array}{l}\text { Hymenaea } \\
\text { courbaril L. var. } \\
\text { stilbocarpa (Hayne) } \\
\text { Lee \& Lang. }\end{array}$ & Jatobá & $\begin{array}{l}\text { afecções pulmonares, dores e } \\
\text { cólicas estomacais, anti-diarréico, } \\
\text { antifúngico, antioxidante, } \\
\text { diurético, expectorante, } \\
\text { hepatoprotetor, } \\
\text { carminativo, adstringente, } \\
\text { estimulante e energético. }\end{array}$ & $\begin{array}{l}\text { suas folhas, } \\
\text { casca, resina, } \\
\text { semente e } \\
\text { fruto }\end{array}$ & $\begin{array}{l}\text { Degradação gástrica, } \\
\text { imunomoduladora, } \\
\text { antifúngico, antimircrobiana, } \\
\text { antibactericida, citóxico } \\
\text { para células cancerígenas. }\end{array}$ & $\begin{array}{l}\text { Suas folhas, } \\
\text { casca, resina, } \\
\text { semente e } \\
\text { fruto }\end{array}$ \\
\hline $\begin{array}{l}\text { Machaerium } \\
\text { aculeatum Raddi. }\end{array}$ & $\begin{array}{l}\text { chimbé-mole, } \\
\text { jacarandá-de- } \\
\text { espinho }\end{array}$ & $\begin{array}{l}\text { Problema de fígado, prisão de } \\
\text { ventre, lavar ferida, úlcera, } \\
\text { diurético. }\end{array}$ & $\begin{array}{l}\text { Cipó, planta } \\
\text { toda }\end{array}$ & Reumatismo & Caule, flor \\
\hline $\begin{array}{l}\text { Machaerium } \\
\text { scleroxylon Tul. }\end{array}$ & $\begin{array}{l}\text { jacarandá caviúna, } \\
\text { jacarandá } \quad \text { da } \\
\text { caatinga, violeta ou } \\
\text { cabiúna vermelha }\end{array}$ & Sensilibizam a pele humana & $\begin{array}{l}\text { Óleo-resina, } \\
\text { caule, } \\
\text { madeira }\end{array}$ & Nada consta & Nada consta \\
\hline $\begin{array}{l}\text { Machaerium } \\
\text { stipitatum (DC.) } \\
\text { Vog. }\end{array}$ & $\begin{array}{l}\text { Conhecida } \\
\text { como sapuva, } \\
\text { sapuvinha, canela- } \\
\text { do-brejo, } \\
\text { jacarandá-roxo ou } \\
\text { pau-de-malho }\end{array}$ & $\begin{array}{l}\text { é utilizada pelos índios na cura } \\
\text { de feridas e infecções na boca } \\
\text { ("sapinho") }\end{array}$ & Casca & Nada consta & Nada consta \\
\hline $\begin{array}{l}\text { Myroxylon } \\
\text { peruiferum L. F. }\end{array}$ & $\begin{array}{lr}\text { cabriúva, } & \text { pau-de- } \\
\text { bálsamo, } & \text { bálsamo } \\
\text { peruviano } & \text { e } \\
\text { bálsamo } & \\
\end{array}$ & Excitante, gripe & $\begin{array}{l}\text { Óleo-resina, } \\
\text { folha }\end{array}$ & Atividade antimicrobiana & $\begin{array}{l}\text { Todas } \\
\text { partes }\end{array}$ \\
\hline $\begin{array}{l}\text { Parapiptadenia } \\
\text { rigida (Benth.) } \\
\text { Brenan }\end{array}$ & $\begin{array}{l}\text { Angico, angico- } \\
\text { vermelho }\end{array}$ & Cicatrizante, atidiarreico & Casca/goma & $\begin{array}{l}\text { Adstringente, expectorante, } \\
\text { antidiarreico, antisséptico, } \\
\text { antihemorrágica. }\end{array}$ & Casca/goma \\
\hline
\end{tabular}

ENCICLOPÉDIA BIOSFERA, Centro Científico Conhecer - Goiânia, v.13 n.23; p. 


\begin{tabular}{|c|c|c|c|c|c|c|}
\hline $\begin{array}{l}\text { Peltophorum } \\
\text { dubium (Spreng.) } \\
\text { Taub. }\end{array}$ & Canafistola & Anticoncepcional & Caule/casca & Nada consta & & Caule/casca \\
\hline $\begin{array}{l}\text { Piptadenia } \\
\text { gonoacantha } \\
\text { (Mart.)J.F. Macbr. }\end{array}$ & Pau-jacaré & Atua contra o câncer & Nada consta & $\begin{array}{l}\text { antiinflamatórios } \\
\text { antialérgicos }\end{array}$ & $\mathrm{e}$ & Caule e folha \\
\hline $\begin{array}{l}\text { Platypodium } \\
\text { elegans Vogel. }\end{array}$ & $\begin{array}{l}\text { Jacarandá } \\
\text { Campo }\end{array}$ & Nada consta & Nada consta & atividade antimicrobiana & & Casca \\
\hline $\begin{array}{l}\text { Schizolobium } \\
\text { parahyba ( Vell.) } \\
\text { Taub }\end{array}$ & Guapuruvu & Nada consta & Nada consta & Ação anti-ofídica & & $\begin{array}{l}\text { Sementes } \\
\text { folhas }\end{array}$ \\
\hline
\end{tabular}




\section{AGRADECIMENTOS}

Á CAPES pelo auxílio financeiro para esse trabalho.

\section{REFERÊNCIAS}

ALBURQUE, U. P. de; LUCENA, R. F. P. de. Métodos e técnicas para coleta de dados. In: ALBURQUE, Ulysses Paulino de; LUCENA, Reinaldo Farias Paiva de. Métodos e Técnicas na Pesquisa Etnobotânica. Olinda: Livro Rápido - Grupo Elógica, 2004. p. 37-62.

ALVES, G.S.P. Estudo etnobotânico de plantas medicinais na comunidade de Santa Rita, Ituiutaba - MG. Biotemas, v. 26, n. 3, p. 231-242, 2013.

AZEVEDO, S.K.S.; SILVA, I.M.; Plantas medicinais e de uso religioso comercializadas em mercados e feiras livres no Rio de Janeiro, RJ, Brasil. 1 Parte da Monografia de Bacharelado da primeira Autora. Acta Botanica Brasílica, p. 185-194. 2006. Disponível em: <http://dx.doi.org/10.1590/S0102-33062006000100017>. doi: 10.1590/S010233062006000100017

BADKE, M.R.; RESSEL, L.B; Plantas Medicinais: O saber sustentado na prática do cotidiano popular. Escola Anna Nery. Revista de Enfermagem, v. 15, n. 1, p.132-139, 2011. Disponível em: <http://dx.doi.org/10.1590/S1414-81452011000100019>. doi: 10.1590/S1414-81452011000100019

BARATA-SILVA, A. W.; MACEDO, R. L. G.; GOMES, J. E.; Potencial de utilização de espécies arbóreas medicinais no Rio Grande do Sul. Revista Científica Eletrônica de Engenharia Florestal, v. 3, n. 6, p.1-6, 2005.

BORGES FILHO, H. C.; FELFILI, J. M. Avaliação dos níveis de extrativismo da casca de barbatimão [Stryphnodendron adstringens (Mart.) Coville] no Distrito Federal, Brasil. Revista Árvore, v. 27, n. 5, p.735-745, 2003.

BRAGA, T.; JORGE, A.; BORGES, E. de L. e; MARTINS, E.; VENÂNCIO, Florística e estrutura da comunidade arbórea de uma floresta estacional semidecidual em Viçosa, MG. Revista Árvore, v. 35, n. 3, p.493-503, 2011.

CUNHA, A. R.; MARTINS, D.; Classificação climática para os municípios de Botucatu e São Manuel, SP. Irriga, v. 14, n. 1, p.1-11, 2009.

FERREIRA, F. M. C.; LOURENÇO, F. J. de C.; BALIZA, D. P. Levantamento etnobotânico de plantas medicinais na comunidade quilombola Carreiros, Mercês Minas Gerais. Revista Verde de Agroecologia e Desenvolvimento Sustentável, v. 9, n. 3, p.205-212, 2014. 
FONSECA, R. C. B.; RODRIGUES, R. R.; Análise estrutural e aspectos do mosaico sucessional de uma floresta semidecídua em Botucatu, SP. Scientia Forestalis, n. 57, p.27-43, 2000.

IMAFLORA, Florestas de valor incentiva nova economia na floresta. Florestas de Valor, n. 1, p. 8, 2014.

LOPEZ, R. E. da S.; SANTOS, B. C. dos. Farmacologia: Bauhinia forficata Link (Fabaceae). Revista Fitos, v. 3, n. 9, p.161-252, 2015.

LORENZI, H.; MATOS, F. J. A.; Plantas Medicinais no Brasil: Nativas e Exóticas. 2ª ed., São Paulo, Instituto Plantarum de Estudos da Flora Ltda, p. 479-480, 2008.

LORENZI, H. Árvores brasileiras: manual de identificação e cultivo de plantas arbóreas do Brasil, v.1, 4⿳a . ed. São Paulo, Instituto Plantarum, p.384, 2002.

LORENZI, H. Árvores brasileiras: manual de identificação e cultivo de plantas arbóreas do Brasil, v.2, 4⿳亠丷a . ed. São Paulo, Instituto Plantarum, p.384, 2002.

MARTINS, S. V. (Org.). Ecologia de florestas tropicais do Brasil. Revista e Ampliada. $2^{a}$. ed., v. 1., p. 371, 2012.

MONTES, L.V; BROSEGHINI, L.P; ANDREATTA, F.S.; ANNA, M.E.S.S.; NEVES, V.M; Evidências para o uso da óleo-resina de copaíba na cicatrização de ferias - uma revisão sistemática. Natureza online. v. 7, n. 2, p.61-67, 2009.

NETO, R.S.; BENTO, M.C.; MENEZES, S.J.M.C.; ALMEIDA, F.S.; Caracterização da Cobertura Florestal de Unidades de Conservação da Mata Atlântica, Floresta e Ambiente, v. 22, n. 1, p. 32-41, 2015. Disponível em: <http://dx.doi.org/10.1590/21798087.058013 >. doi: 10.1590/2179-8087.058013

NOBRE, A. D. O Futuro Climático da Amazônia. 1a. Ed., Articulación Regional Amazônica, Centro de Ciência do Sistema Terrestre - Instituto Nacional de Pesquisas Espaciais Instituto Nacional de Pesquisas da Amazônia, p. 42, 2014.

RAMOS, V. S. Árvores da Floresta Estacional Semidecidual: Guia de Identificação de Espécies. 2a . Ed., São Paulo, Edusp, 2015.

RODRIGUES, V. E. G.; CARVALHO, D. A. Levantamento Etnobotânico de Plantas Medicinais no Domínio do Cerrado na Região do Alto Rio Grande - Minas Gerais. Ciência e Agrotecnologia, v. 25, n. 1, p. 102-123, 2001.

RODRIGUES, V. E. G.; CARVALHO, D. A. Plantas Medicinais nas Florestas Semideciduais. Editora UFLA, 2010 
SANTOS, A. J. dos; HILDEBRAND, E., PACHECO, C. H. P.; PIRES, P. de T. de L.; ROCHADELLI, R. Produtos não madeireiros: conceituação, classificação, valoração e mercados. Revista Floresta, v. 33, n. 2, p. $215-224,2003$.

Disponível em: <http://dx.doi.org/10.5380/rf.v33i2.2275>. doi: 10.5380/rf.v33i2.2275

SANTOS, M. F. Composição e estrutura arbórea em floresta estacional semidecidual no Espinhaço Meridional (Serra do Cipó, MG). Rodriguésia, v. 63, n. 4, p.985-997, 2012.

Disponível em: <http://dx.doi.org/10.1590/s2175-78602012000400015>. doi: 10.1590/s2175-78602012000400015

VIEIRA, M.C; BRATI, C.; ZÁRATE, N.A.H.; OLIVEIRA, A.P.A.; MARAFIGA, B.G.; FERNANDES, S.S.L.; Levantamento de Plantas Medicinais Nativas da Fazenda Azulão em Dourados- MS. Revista Brasileira de Plantas Medicinais, v.15, n.4, p. 675-683, 2013. Disponível em: <http://dx.doi.org/10.1590/S1516-05722013000500008>. doi: $10.1590 /$ S1516-05722013000500008

ZAKIA, M.J. B. et al (Org.). WORKSHOP SOBRE FLORESTAS NATIVAS: Propostas para subsidiar um plano de implantação de florestas nativas com viabilidade econômica e ecológica. Piracicaba: IPEF, p. 47, 2012. Disponível em: <http://dx.doi.org/10.5007/2175-7925>. doi: 10.5007/2175-7925 